NBER WORKING PAPER SERIES

\title{
HEALTH KNOWLEDGE AND NON-PHARMACEUTICAL INTERVENTIONS DURING THE COVID-19 PANDEMIC IN AFRICA
}

\author{
Anne E. Fitzpatrick \\ Sabrin A. Beg \\ Laura C. Derksen \\ Anne Karing \\ Jason T. Kerwin \\ Adrienne Lucas \\ Natalia Ordaz Reynoso \\ Munir Squires \\ Working Paper 28316 \\ http://www.nber.org/papers/w28316 \\ NATIONAL BUREAU OF ECONOMIC RESEARCH \\ 1050 Massachusetts Avenue \\ Cambridge, MA 02138 \\ January 2021
}

We gratefully acknowledge generous funding from the Joseph P. Healey Research Grant and the Jameel Poverty Action Lab (J-PAL). For excellent research management and assistance we thank Henry Atimone, Charlotte Burlingame, and Heather Wong. We thank the entire field team in each country for their efforts in completing these surveys. We thank Marcella Alsan, Emily Beam, Alan de Brauw, Janet Currie, David Molitor, and Laura Wherry for helpful comments. All errors are our own. The views expressed herein are those of the authors and do not necessarily reflect the views of the National Bureau of Economic Research.

NBER working papers are circulated for discussion and comment purposes. They have not been peer-reviewed or been subject to the review by the NBER Board of Directors that accompanies official NBER publications.

(C) 2021 by Anne E. Fitzpatrick, Sabrin A. Beg, Laura C. Derksen, Anne Karing, Jason T. Kerwin, Adrienne Lucas, Natalia Ordaz Reynoso, and Munir Squires. All rights reserved. Short sections of text, not to exceed two paragraphs, may be quoted without explicit permission provided that full credit, including $(\odot$ notice, is given to the source. 
Health Knowledge and Non-Pharmaceutical Interventions During the COVID-19 Pandemic in Africa

Anne E. Fitzpatrick, Sabrin A. Beg, Laura C. Derksen, Anne Karing, Jason T. Kerwin, Adrienne Lucas, Natalia Ordaz Reynoso, and Munir Squires

NBER Working Paper No. 28316

January 2021

JEL No. I12,I15,I18,O12

\begin{abstract}
Providing health information is a non-pharmaceutical intervention designed to reduce disease transmission and infection risk by encouraging behavior change. But does knowledge change behavior? We test whether coronavirus health knowledge promotes protective risk mitigation behaviors early in the COVID-19 pandemic across four African countries (Ghana, Malawi, Sierra Leone, and Tanzania). Despite reputations for weak health sectors and low average levels of education, health knowledge of the symptoms and transmission mechanisms was high in all countries in the two months after the virus entered the country. Higher knowledge is associated with increased protective measures that would likely lower disease risk with one exceptionknowledge is inversely correlated with social distancing. Respondents largely adhered to mask mandates and lockdowns, but continued coming into contact with others at small, informal gatherings, gatherings not affected by mandates. Knowledge alone appears unlikely to reduce all risky activities, especially gatherings within other people's homes. Even early in the pandemic income loss or stress were commonly reported. Our results suggest that early and consistent government provision of health information, likely reduced the severity of the pandemic in Africa but was not a panacea.
\end{abstract}

Anne E. Fitzpatrick

University of Massachusetts-Boston 100 Morrissey Blvd.

Boston, MA 02125

anne.fitzpatrick@umb.edu

Sabrin A. Beg

University of Delaware

418 Purnell Hall

Newark, DE 19716

sabrin.beg@gmail.com

Laura C. Derksen

University of Toronto

105 St. George Street

Toronto, Ontario

M5S 3E6 Canada

laura.derksen@utoronto.ca
Anne Karing

Princeton University

Department of Economics

530 Evans Hall \#3880

Berkeley, CA 94720-3880

United States

akaring@princeton.edu

Jason T. Kerwin

Department of Applied Economics

University of Minnesota

1994 Buford Ave.

316C Ruttan Hall

Falcon Heights, MN 55108

jkerwin@umn.edu 
Adrienne Lucas

Lerner College of Business and Economics

University of Delaware

419 Purnell Hall

Newark, DE 19716

and NBER

alucas@udel.edu

Natalia Ordaz Reynoso

Department of Applied Economics

University of Minnesota

nordazreynoso@gmail.com

Munir Squires

UBC Economics

6000 Iona Drive

Vancouver, BC, Canada, V6T 1L4

munir.squires@ubc.ca 


\section{Introduction}

As the coronavirus pandemic emerged, policy makers were concerned that the health impacts of the pandemic may be disproportionately borne by lower income countries because of their weak health sectors and their populations' inability to socially isolate (United Nations 2020) - This concern was particularly acute in Africa where despite younger populations, many residents have co-morbidities that would result in more severe symptoms, pushing weak health infrastructures past their limits (Lone and Ahmad 2020). Absent a vaccine, countries relied on information campaigns to encourage individual non-pharmaceutical interventions (NPIs)-social distancing, hand washing, and mask wearing- and imposing community NPIsclosures of schools, businesses, and/or houses of worship. These NPIs do not rely on the sophistication or capacity of the health sector but instead depend on voluntary behavior change. Whether NPIs can be successful in lower income countries is an empirical questiondo people understand and trust the information, adhere to mandates, and have the capacity and ability to change their risky behaviors?

We analyze the level of health knowledge and whether health knowledge increased the adoption of NPIs such as mask-wearing and social distancing using detailed survey data from four African countries collected early in the pandemic, early April through mid-June, less than 2 months after the virus was first reported in each country. Our countries represent varied geography-West, East, and Southeastern-and income-lower-middle and low income. We asked people in Ghana, Malawi, Sierra Leone, and Tanzania about their knowledge of coronavirus symptoms and transmission mechanisms, their and their household's experience with social distancing, and how their households were affected by the pandemic. With unified measures across four countries, we compare the knowledge, risk mitigation practices, and consequences of the pandemic (including associated lockdowns).

We have four main findings. 1) We find high levels of knowledge that are associated with increased take-up of risk mitigation measures-the the average respondent correctly reported 3 symptoms, 2 transmission mechanisms, and almost no incorrect symptoms or transmission 
mechanisms and undertook 2.3 "effective" protective measures. ${ }^{1}$ 2) Early government action, including messaging, mask mandates, and lockdowns led to meaningful behavior change-we found about a 50 percentage point gap in mask use between the mask mandate (Ghana and Sierra Leone) and non-mask mandate countries (Malawi and Tanzania) with a similar gap in the likelihood of coming into close contact with another person at a house of worship between countries that mandated their closure (Ghana and Sierra Leone) and those that did not (Malawi and Tanzania). 3) Knowledge was not sufficient for adoption of social distancing, behavior that is likely the most effective at reducing disease transmission. The average respondent patronized 3.1 different places in the last week where they were in close physical contact with people outside of their household, often in places satisfying basic needs, i.e. transportation, markets, and shared toilet facilities. However, non-essential contacts were also common-46 percent of respondents on average reported visiting another person's home in the previous week. 4) Across all countries this pandemic and the policies enacted in response, had severe impacts relatively early-54 percent of respondents reported income loss as a result of the pandemic and 49 percent reported increased stress.

Our paper contributes to three related literatures. First we contribute to the growing literature on how to manage and mitigate the effects of pandemics through NPIs. We show that information is an effective NPI as it increases protective health behaviors and encourages behavior that mitigates risk similar to the existing literature on information regarding sexual partners (Dupas 2011), unsafe water (Madajewicz et al. 2007), hygiene (Jalan and Somanathan 2008; Cairncross et al. 2005 ), and in particular can be useful during this pandemic (Haushofer and Metcalf 2020). In particular, we find a correlation between health knowledge and hand washing, mask-wearing, and other risk mitigation measures. However, the effectiveness of information can depend upon other factors, including the costs of following the information (Kremer et al. 2007), household bargaining power (Dupas 2011), a respondent's beliefs regarding their eventual likelihood of contracting the disease (Kerwin

\footnotetext{
${ }^{1}$ Effective protective measures are wearing a mask, washing hands, using hand sanitizer, and reducing social contacts (Cowling and Aiello 2020).
} 
2020 ), their life expectancy (Oster 2012), or who issues the directives (Kao et al. 2020). In lower income countries with relatively expensive risk coping strategies, individuals may not be able to reduce their risk to desired levels despite their level of knowledge. Consistent with that intuition, we show that health knowledge is positively correlated with the number of times in the past week an individual was in close contact with those outside of their household (i.e., knowledge is negatively correlated with social distancing).

Second, our results contribute to a broader understanding of the combined effects of a pandemic and related lockdowns. Early in the pandemic the direct health effects of the disease were a focus, and we show that only 4 percent of households were directly infected by the virus, while, about half reported income loss with a similar amount reporting increased stress. Notably, the stress consequences were not concentrated among those who had lost income, but rather appear to be a more general phenomenon. Parents, in particular, report additional stress, a potentially worrisome situation in a context where rates of child abuse are high (Meinck et al. 2016; Badoe 2017).

Third, our results contribute to the literature on the differential experience of the pandemic across countries. We are the first to use harmonized microdata across lower income countries on behavior change in response to the pandemic. The majority of the existing literature consists of descriptive statistics and does not discuss correlates of NPI use, nor seeks to explain the role of policy in contributing to differential NPI use across countries. While existing literature has focused on the role of demographics (Goldberg and Reed 2020; Castex et al. 2020a; Castex et al. 2020b), government policies (Rannan-Eliya et al. 2021), or political economy (Chiplunker and Das 2020; Alsan et al. 2020 ), less work has used microdata on what role, if any, individual risk mitigation practices play at explaining COVID-19 prevalence worldwide (Rannan-Eliya et al. 2021). In the US, Alsan et al. (2020) showed the relationship between sociodemographic characteristics and reported knowledge and behavior in the US. We show that individual knowledge increases mitigation measures, but does not curtail all risky behaviors, across four countries. We show that mandates help individuals 
adopt risk mitigation strategies. Together, both of these findings suggest that both individual risk mitigation strategies and high rates of compliance with mandated, community NPIs may also contribute to the relatively low rates of COVID-19 cases in Africa as compared to richer countries. Despite the lack of a direct health effect, we also add to the growing evidence that the social and economic consequences of the pandemic were severe, with projections of continued negative effects for some time to come (Erokhin and Gao 2020; Amare et al. 2020; Jain et al. 2020; Mahmud and Riley 2020; Josephson et al. 2020).

Finally, we contribute to the literature on the elements of a successful public health campaign. Vaccinations have been successful at reducing the burden of disease and increasing life expectancy, in part because once an individual achieves immunity through vaccination no additional action is necessary by them (Karing 2020). In contrast, attempts to reduce malaria transmission through regular bed net use and reduce HIV/AIDS transmission with adherence to pharmaceutical regimes and eliminating risky behaviors have been more complicated (e.g. Lucas 2010, Lucas and Wilson 2018). Our contradiction between knowledge and some forms of action are similar to the understanding that developed during the behavior change-communication messaging campaigns during the HIV epidemics in the early 2000s (Lo et al. 2016 ). While abstinence-only education was ineffective at reducing transmission, encouraging a suite of other risk mitigation strategies such as using condoms was more effective, particularly for high risk groups (Okafor et al. 2017). However, continued use of condoms was difficult to individuals to maintain when faced with typical levels of risk (Foss et al. 2007). In the same way, individuals adopted risk mitigation measures in response to the coronavirus threat, but were unable to voluntarily adhere to extreme measures such as reducing all extraneous contacts. While early in the pandemic our results indicate households were engaging in relatively lower-cost protective measures, we caution that such protective measures may wane as individuals find ongoing efforts burdensome as they wait for a vaccine. We show that despite the important role of information as a non-pharmaceutical intervention, even knowledgable households perform constrained optimization that might not allow them 
to fully realize the benefits of risk-mitigation.

\section{Background}

\subsection{Country Details}

We selected four African countries that represent a wide dispersion of geography, population size, and income. Both Ghana and Sierra Leone are in West Africa, while Malawi is in the southeast and Tanzania is in East Africa. Tanzania has a population of 59 million, Ghana 30 million, Malawi 21 million, and Sierra Leone 7 million people. Based on gross domestic product per capita in 2019, purchasing power parity adjusted international dollars, Ghana was the richest $(\$ 5637)$ and Malawi the poorest $(\$ 1104)$ with Tanzania $(\$ 2771)$ and Sierra Leone (\$1790) between the two, making Ghana and Tanzania lower-middle income and Sierra Leone and Malawi low-income (World Bank 2020). Countries also varied substantially in their hospital bed capacity, reflective of their weak health infrastructures. In the most recent year data were available, for every 10,000 population, Ghana had 9, Malawi had 13, Tanzania had 7, and Sierra Leone had 4 hospital beds (WHO 2020). For comparison, the United States had 28.7 beds per 10,000 population. Finally, countries vary substantially in their educational attainment and literacy rate. Among those over 15, the literacy rate is relatively high in Ghana and Tanzania (79 and 78 percent, respectively). Literacy is lower in Malawi (62 percent) and Sierra Leone (43 percent).

\subsection{Continent-Wide Responses}

Health ministers across Africa acted early in response to the pandemic. Approximately one month after the January 22, 2020 consensus that COVID-19 transmitted between humans and in recognition of the potential impact of the pandemic, African health ministers established a coronavirus task force to create a continent-wide strategy (Osseni 2020). This 
action was earlier than strategies and plans announced by richer countries. ${ }^{2}$ On March 11, the WHO declared the coronavirus a pandemic, and on June 5 the WHO updated its guidance on mask-wearing.

Governments, international bodies, and nonprofits enacted public health messaging campaigns, often in local languages, across the continent starting in early March. In addition to any programs by specific countries, UNICEF began large-scale public health messaging campaigns to improve awareness about the coronavirus. To combat misinformation, starting in April the WHO partnered with Twitter, Facebook, Tencent and TikTok to ensure the content on their platforms was accurate, set up websites to disseminate accurate information in local languages, and engaged Google to allow for targeted search of coronavirus information in local languages. In addition to private sector mobilization, the World Bank also issued $\$ 14$ billion in grants to affected countries, with an intention to deploy up to an additional $\$ 16$ billion over the next year and half to help countries cope with containing the public health threat. Other major NGOs, including Catholic Relief Services, Living Water International, Sightsavers, the Red Cross, Save the Children, repurposed their campaigns from other diseases and ailments to focus on the coronavirus, including messaging targeted to increasing awareness and induce risk mitigation measures, such as hand washing. Individual philanthropists also contributed to the disaster preparedness. Chinese billionaire Jack Ma, for example, shipped a cargo flight containing 6 million medical items in late March to be distributed across the continent.

\subsection{Country Experiences with the Pandemic}

In addition to information campaigns, many African countries took a more active approach to instigating behavior change through public service announcements, and community-level

\footnotetext{
${ }^{2}$ The United States suspended some travel from China on January 31 and from Europe March 11, suspended visa services March 18, and closed the Canadian and Mexican borders to non-essential travel on March 23. Although the European response varied by country, the EU began repatriating citizens from China on February 1, set up a response team on March 2, and announced a coordinated response March 13. The WHO special envoy advised countries to act quickly and decisively on March 30.
} 
NPIs such as lockdowns and mask mandates. Rates of NPIs are notably higher in Africa than on other continents (Zheng et al., 2020). Table 1, Panel A summarizes the experience of each country in our sample with the pandemic.

\section{[Table 1 about here]}

Ghana's first diagnosed case was in March 12, and on March 16, the government closed churches, schools, and instituted an expansive lockdown that was partially lifted May 20. A nationwide mask mandate was instituted April 24. By July, Ghana released a miniseries called "Corona Life" to promote hygiene and sanitation, instituted enhanced public sanitation programs at markets, and began a testing and tracing program (Africa Studies 2020). Schools are scheduled to reopen January 2021. As of November 2 , there had been 48,200 cases and 316 deaths.

Malawi's first case was reported on April 2. The goverment began an extensive information campaign, including going door-to-door providing health information (Masina 2020). The government proposed a complete lockdown to start on April 18, but the high court of Malawi blocked the lockdown in the absence of income protections and no lockdown occurred. The government enacted a mask mandate on August 7. As of November 2, 2020, Malawi reported 5,933 cases and 183 deaths.

Sierra Leone's first case of the coronavirus was documented March 30. The lockdowns in Sierra Leone were brief, but almost total: two separate 3-day total lockdowns in which all non-essential businesses, schools, and churches were closed and travel was restricted. The government also instituted a mask mandate on April 24. By summer, the government (in coordiantion with the UNDP) had mobilized to provide lessons and trainings, including weekly videos on social media and community campaigns in local langauges (UNDP 2020;GRID3 2020). As of November 2, Sierra Leone reported 2,366 cases and 74 deaths.

Tanzania reported its first case on March 16, closing schools and banning mass gatherings the next day. While there has been no nationwide mask mandate, several areas within the country, including Dar es Salaam mandated masks on April 18. In contrast to the 
other countries, the govenment prohibited media from reporting on the pandemic, prompting outrage from Reporters without Borders and other civil liberties groups. After reporting 509 cases and 21 deaths on May 8, on May 9 the government stopped reported coronavirus-related statistics, declared that their country was free from the virus.

Our analysis uses individual survey data to show the commonalities and differences among these countries in their resulting experiences with the pandemic. Together, our results provide additional insight into the observation that the health impacts of the coronavirus pandemic have not been as devastating as feared, and that most of the decreases in years of lost life are concentrated in richer countries (Marois et al. 2020).

\section{Data}

Our data span four countries and three months. We collected our data through phone-based surveys that occurred from April 10 to June 19, with variation by country. Panel B of Table 1 provides the exact dates of each survey, along with additional details of data collection. To reach many respondents in a short period of time, we used existing sample frames from studies with previously collected phone numbers. As a result we had high response rates (averaging over 62 percent) and were able to field the surveys early in the pandemic, but our data are not nationally representative. Data from Ghana were collected from teachers, head teachers (i.e. school principals), and circuit supervisors (school supervisors who oversee clusters of eight geographically proximate schools) as part of a follow-up for a school-based differentiated instruction intervention from Beg et al. (2020). Respondents from Malawi are men who frequent bars in the Zomba district and were part of an HIV study by Derksen et al. (2020) . Respondents in Sierra Leone were residents of Freetown who participated in a pilot of an intervention designed to improve safety on public transportation (Karing 2020). Respondents in Tanzania were microenterprise owners participating in a study on the effects of kinship taxation (Squires 2020). Data were collected starting just over 3 weeks after the first case in Sierra Leone and Tanzania and 8 weeks after the first case in both Ghana and 
Malawi.

Respondents in each country were asked the same questions about their coronavirus knowledge and related behaviors and the effects the pandemic and related government actions on their households. Respondents volunteered their responses and were not prompted about each individual symptom, mechanism, or location. ${ }^{3}$ Following public health guidance early in the pandemic, we consider hand-washing, social distancing, using hand sanitizer, wearing a mask, not sharing food, and not shaking hands as effective preventative measures. We highlight the role of masks in our discussion out of growing evidence of the high effectiveness of masks at reducing transmission and death (Eikenberry 2020; Gandhi et al., 2020; Lyu and Wehby 2020; Murray 2020). The correct transmission mechanisms are airborne, touching others, touching contaminated surfaces, and asymptomatic transmission. The correct symptoms were coughing, fever, fatigue, difficulty breathing, loss of taste or smell, headache, and sore throat (although results are not sensitive to the inclusion of less commonly reported symptoms, such as sneezing.

We additionally collected demographic details from these respondents. Because educational systems are not uniform across countries, we created three educational categories across transition points common to all countries-no schooling, some schooling but less than secondary school completion, and secondary school completion or more. Table 2 contains summary statistics of the sample demographics. While the sample characteristics vary by country, our overall sample is about 34 years old, 75 percent male, almost all have at least one child in their household.

\footnotetext{
${ }^{3}$ Appendix A contains the exact questions. Questions were open-ended and interviewers used pre-coded options to record responses but did not prompt respondents. Therefore, our results can be considered an underestimate of true knowledge and risk mitigation practices, and primarily reflect the salience of an individual symptom, risk mitigation mechanism, or way that they had been affected. In Tanzania, for the first 149 responses, individuals were asked in sequence about whether they had been to a particular location in the past 6 days. However, due to concerns of placing too high a burden on respondent time, the question was switched to open-ended instead of prompted for the rest of that country and the other countries. We include a control for the mode of question administration, and corelations between knowledge and contacts results are robust to excluding those early results (not shown). In Sierra Leone, the question about how respondents were affected by the coronavirus was inadvertently omitted. However, other questions about respondent well-being were asked, and so we harmonize responses for those topics . Results are robust to excluding Sierra Leone.
} 
[Table 2 about here]

\section{Empirical Strategy}

We first present evidence on the average levels of knowledge and preventative measures taken across countries. We then test the relationship between demographics and knowledge and behavior by estimating

$$
Y_{i c}=\alpha+\Gamma^{\prime} X_{i c}+\lambda_{c}+\varepsilon_{i c}
$$

where $Y_{i c}$ is knowledge or behavior $Y$ for respondent $i$ in country $c, X_{i c}$ are individual level demographic covariates, and $\lambda_{c}$ are country fixed effects. ${ }^{4}$ Our outcomes of interest are the number of correct symptoms, the number of correct transmission mechanisms, the number of effective protective measures taken, and the number of contacts. The coefficients on the individual demographics, $\Gamma$, tell us the relationships net of country-level differences while the country fixed effects elucidate the differences between countries net of demographic differences in the sample.

To test whether health knowledge is correlated with risk mitigation health behaviors we estimate the following equation:

$$
Y_{i c}=\alpha+\beta_{1} \text { Symptoms }_{i c}+\beta_{2} \text { Transmission }_{i c}+\Gamma^{\prime} X_{i c}+\lambda_{c}+\varepsilon_{i c}
$$

where $Y$ is a protective health behavior undertaken by respondent $i$ in country $c$, Symptoms and Transmission are the number of correct symptoms and transmission mechanisms the respondent reported, $X_{i c}$ are the individual level demographic covariates considered above, and $\lambda_{c}$ are country fixed effects. In this specification our focus is on $\beta_{1}$ and $\beta_{2}$-the relationships between knowledge and behavior, net of demographic characteristics. ${ }^{5}$ Our outcomes

\footnotetext{
${ }^{4}$ Whether respondents were given choices or responded freely changed during the survey in Tanzania. We control for this change in all specifications.

${ }^{5}$ In the appendix, in lieu of country fixed effects, we provide estimates with enumerator fixed effects in
} 
of interest are the number of effective protective measures taken and the number of contacts.

\section{Results}

\subsection{Average Levels of Knowledge, Actions, and Pandemic Effects}

Table 3, contain the averages both within each country (columns 1 to 4) and across countries (column 5) for the knowledge and behavior questions, with column 6 providing the p-value associated with joint equality across all samples.

[Table 3 about here]

Almost everyone (99 percent) had at least some correct transmission knowledge with the average person listing 2 (of 4). Interestingly, despite all the differences between the countries and the samples, we fail to reject that the number of correct transmission mechanisms listed is the same across countries. We also find very high symptom knowledge (Panel B)-only 2 percent of respondents could list no correct symptoms, with the average person naming 3 symptoms. In our data, with voluntary response, 55 percent of respondents report 3 or more correct symptoms, with a maximum of 8. By comparison, Alsan et al. (2020) found that 87 percent of respondents could correctly identify the top three symptoms of coronavirus out of a list. Geldsetzer (2020) also finds high rates of knowledge (80-85 percent) in the US and UK using voluntary response, although the number of symptoms given is not reported. As with transmission knowledge, we fail to reject equality across countries.

The protective measure means appear in Panel C. Despite people knowing statistically indistinguishable numbers of transmission mechanisms across countries, respondents' actions vary by country. Perhaps most surprising was that in Malawi almost 13 percent of the sample was taking no protective measures. This relatively high average in Malawi may reflect the

sampling frame - men who frequent bars may be less health conscious or disproportionately likely to take risks. In the other countries, almost all respondents were taking at least one case enumerator coronavirus knowledge affects recorded responses (Ordaz Reynoso and Kerwin 2020 ). 
protective measure. In the two countries without mask mandates (Malawi and Tanzania), fewer than 30 percent of respondents reported wearing a mask, while over three-quarters of respondents reported wearing a mask in the two countries with mask mandates (Ghana and Sierra Leone). Over 80 percent of respondents in each country, statistically equivalent across countries, offered hand washing as one protective measure they were taking. Appendix Figure B1 graphically depicts the portion of people in each country who claimed to be taking each measure.

Despite over 50 percent of respondents in each country knowing that reducing exposure to others is a way to protect against infection, over 70 percent of respondents reported having contact within two meters of someone outside of their household in the last week, averaging 3 such places where that contact occurred. Further, slightly more than halfof respondents with children reported that their children had close contacts with others outside their household in the last week. Across all four countries, the most common place that people had contacts with others was the market (Appendix Figure B2 presents a bar chart of the most commonly mentioned contact locations by country). For Ghana, Sierra Leone, and Tanzania the next places of contact in descending order were other houses, public transportation, and work. In contrast, work was reported almost as frequently as the market in Malawi. This average may also reflect the sampling frame in Malawi-men patronizing bars may be disproportionately likely to still be employed and are also in urban areas.

The full responses appear in Appendix Table B1, disaggregated by whether contacts occurred at "informal" (i.e., smaller gatherings or contacts that are incidental to the activitymarkets, another person's house, transportation, communal wash facilities, or takeout dining) or "formal" (i.e., organized events or larger gatherings where contact is assumed-work, worship, dine-in restaurant, weddings or other celebrations or festivals, or other large meetings) activities. Informal activities are less likely to be affected by government lockdowns and would therefore be primarily affected by voluntary behavior change.

The relative magnitude of contacts at formal vs. informal activities could be partially 
driven by government policies in effect at the time of data collection that closed businesses and resulted in canceled formal gathering opportunities. Informal gatherings are still very commonly reported in all countries, suggesting that mandates would not reduce this sort of risky behavior. Instead, the bulk of social contacts in all countries occur where mandates would likely not be enforced or not be binding. However, our data suggest that lockdowns are effective at reducing large gatherings, such as at houses of worship or restaurants. For example, enforced mandates of closures of houses of worship resulted in virtually no contacts at those locations for Ghana and Sierra Leone. ${ }^{6}$ Rates of informal contacts may be high because many of the locations of informal contact lack readily available substitutes in the developing country context. For example, in richer countries people can rely on grocery delivery or refrigerator storage to limit market trips, uncommon features in lower income countries. Home visits were also frequent-on average 48 percent of respondents across all countries visited in another person's home. While such visits have fewer points of contact, the secondary transmission rate within an enclosed home can be as high as 35 percent (Liu et al. 2020). Our data suggest that mandates potentially reduced large gatherings (aside from markets), and substantially reduced the number of contacts, but that close encounters with others are still commonly reported.

In Table 4, we show that respondents vary substantially in their experiences with the coronavirus and associated lockdowns. Although very few individuals were affected directly in terms of health of themselves or a loved one, mental health and economic impacts of the lockdown were commonly reported.

\section{[Table 4 about here]}

Stress was the most common effect of the pandemic in Ghana, and in the top three of all reported effects in the other two countries. An online poll similarly found increases in reported stress during the lockdown period in Ghana (Asiamah et al 2020). Reduction

\footnotetext{
${ }^{6}$ In Tanzania, houses of worship remained open. In Malawi, gatherings of more than 100 people were outlawed, including at households of worship. By contrast, in Sierra Leone and Ghana houses of worship were ordered closed.
} 
of income was the most common effect of the pandemic in Malawi, and was also frequently mentioned in the other countries. The high amount of income loss is particularly noteworthy in Malawi because it did not have a government-mandated lockdown. Having children home from school was another frequently mentioned effect of the pandemic. In Appendix Table B2, we show that the impact on stress is separable from the impact on income. In other words, stress is a commonly felt by-product of the pandemic and is not only felt among those that have lost income, or only in countries that had a lockdown.

\subsection{Correlates of Knowledge and Behavior}

In this sub-section we combine the data from all four countries to consider the correlation between sociodemographic characteristics and knowledge and behavior as well as country-

specific differences, estimates of Equation 1 with a separate outcome each time. The results appear in Table 5. Net of country fixed effects, knowledge of correct symptoms (column 1) is statistically positively correlated with age and increases with educational attainment (relative to no education). Knowledge of correct transmission mechanisms (column 2) is positively related to education. For both of these knowledge outcomes, the other three countries have lower levels than Ghana, the omitted category and richest country in our sample.

Taking increased protective measures is not statistically related to education (column 3). Males and individuals in households with children are associated with more protective measures, while those living in rural areas take fewer measures. As with the knowledge outcomes, all of the point values on the country fixed effects are negative relative to Ghana, the omitted country. None of the sociodemographic covariates besides gender-men have more contacts-have a statistically significant relationship with the number of social contacts (column 4). Respondents in both Malawi and Tanzania have more contacts relative to Ghana, net of demographic differences.

Although individual characteristics included in our specification explain little of the vari- 
ation of symptom or transmission knowledge (4 percent), our independent variables explains nearly 47 percent of the variation in social contacts. Most of the variation in contacts is across countries, not within, potentially reflective of the messaging and political economy surrounding the coronavirus experience.

[Table 5 about here]

\subsection{Relationship Between Knowledge and Behavior}

In Table 6, we show that health knowledge is positively correlated with behaviors that protect individuals against the coronavirus, whether or not we control for sociodemographic controls. Specifically, knowledge of coronavirus transmission mechanisms and symptoms is positively related to taking more risk mitigation measures - each correct symptom known is associated with an additional 0.23 protective measures and each additional transmission mechanism known is associated with another 0.40 effective protective measures. Despite the correlations found in Table 3 between knowledge and sociodemographic controls, these point values are nearly identical with the inclusion of those controls (column 2). Results for individual outcomes are in Appendix Table B3. Individuals with knowledge of either symptoms or transmission mechanisms report decreasing their contacts and hand shaking, and increasing hand washing, hand sanitizing, and mask wearing. ${ }^{7}$ These results are evidence that information makes individual-level NPIs more effective by encouraging risk mitigating, protective practices.

However, health knowledge does not increase the level of social distancing. In Table 7, we estimate the correlation between knowledge and the number of contacts that the respondent reported in the previous week, controlling for country fixed effects and sociodemographic controls. In contrast to the results in Table 6 that showed higher knowledge resulted in more

\footnotetext{
${ }^{7}$ Despite small sample sizes when analyzed by country, in each country symptom and transmission knowledge are positively related to the number of protective measures, (see Appendix Table B4). Knowing an additional symptom is associated with an increase of 0.10 (Sierra Leone) to 0.33 (Malawi) additional protective measures and knowing an additional transmission mechanisms with an increase of 0.20 (Malawi) to 0.35 (Tanzania) additional protective measures.
} 
protective measures, higher knowledge of coronavirus transmission mechanisms are positively correlated with the number of contacts, indicating those with more knowledge undertook additional risky behaviors (column 1). These results lie in contrast to the results in Table 6: despite reporting more effective protective measures individuals with more knowledge were more likely to report more contacts. This coefficient remains positive and statistically significant even after controlling for the number of other protective measures (column 2). Notably, other protective measures are also positively correlated with the number of social contacts, suggesting that individuals may be compensating from their increased social contacts with increasing other risk mitigation measures.

In column 3, we consider whether information is effective at reducing "formal" contacts: the number of times an individual went to a location that would potentially be affected by a lockdown (religious services, dining at restaurants, meetings, or other events). Consistent with the results on total number of contacts, our analysis shows that knowledge does not reduce the number of formal contacts. Therefore, individuals with higher knowledge are patronizing both areas that would and would not be affected by a potential lockdown. In particular, as Appendix Table B5 shows, knowledge is positively correlated with going to other people's homes and taking public transport, suggesting more informed individuals are more likely to interact with others in casual settings that might have lower perceived risk.

In Appendix Figure B3, we plot the number of protective behaviors taken relative to a person with 0 reported contacts to test if individuals relatively more exposed to the coronavirus are more likely to engage in protective measures. For individuals with only 1 or 2 contacts there is a weakly negative relationship. However, once an individual reports three or more contacts, there is a weak, but positive relationship: as individuals frequent more places, the number of protective behaviors that the individual engages in also tends to increase. Although some estimates are not different than zero, these results suggest some degree of risk compensation. Maintaining social distancing appears hard, and individuals with knowledge compensate by engaging in other risk mitigation measures. However, for 
the specific outcome of mask-wearing, a highly effective way to reduce transmission in the presence of close contacts, additional contacts are not associated with a higher likelihood of mask wearing (see Appendix Figure B4), and the correlation is not differential according to health knowledge (not shown).

Those with more contacts could have increased knowledge due to discussing the ongoing pandemic. If true, then knowledge would be increasing during the course of our data collection. In Figure 1, we measure the average knowledge of coronavirus symptoms and transmission by interview date in each country. In each country, the time trend of knowledge is relatively flat, suggesting that average knowledge of the disease was not growing over time. As our question regarding contacts was in the previous 7 days, together these facts suggest that individuals were not acquiring knowledge as a result of their higher social contacts, but rather had knowledge and continued with relatively high rates of contacts. ${ }^{8}$

\section{Discussion and Conclusion}

In this paper we examine the role of information as a non-pharmaceutical intervention to induce risk mitigation behaviors during the coronavirus pandemic. We find that knowledge of the coronavirus symptoms and transmission mechanisms is relatively high. Information is positively correlated with reports of other non-pharmaceutical interventions that mitigate the spread of the coronavirus, such as hand washing, mask wearing, decreased social contacts, and using hand sanitizer. Relatively high rates of use of these measures early on in the pandemic may partly explain why Africa has had relatively few deaths per capita compared to richer regions. Across the four countries we study, the same high rates of knowledge were found both early and later during data collection.

However, we find that health knowledge is either not correlated with or positively related to a particular risky behavior, the number of social contacts that an individual has had in the

\footnotetext{
${ }^{8}$ Sierra Leone and Tanzania have a weak positive trend in mask wearing, but social distancing has no clear trend in any country (not shown).
} 
past seven days. As a result, health knowledge is not clearly related to social distancing, a key mechanism to controlling the spread of the coronavirus. Many of the places where individuals have contact with others lack low-risk alternatives. For example, grocery deliveries may be expensive or unavailable, particularly in rural areas. Car ownership is also less common in developing countries, making public transportation more essential for travel. In addition, many individuals patronize other people's homes. Limiting these sorts of informal settings would likely be more difficult to enforce during a lockdown. While closing houses of worship was effective at reducing the rates of people attending those locations, voluntary behavior change, even among those with relevent health knowlege, is unlikely to produce desired effects. These results have important insights for policymakers who rely upon voluntary behavior change to reduce disease risk, and inform the likelihood of success as countries may consider another wave of lockdowns as they wait for a vaccine.

Our survey also highlights that mental health issues may be an important additional consideration for policymakers to consider moving forward. While much attention has been paid to the potential mortality impacts of the coronavirus, our results indicate that mental health is also a pressing concern. Across all countries, respondents commonly report stress as an impact of the pandemic, along with income loss, even in countries that did not institute a lockdown. Although the negative effects of income loss are first-order, the potential negative consequences of long-term stress should be given appropriate consideration, particularly in the context of children at home from school at risk of abuse.

Overall our results indicate that although knowledge is helpful, more aggressive support for individuals to assist them in maintaining compliance with lockdowns and allowing them to minimize contacts with others will maximize the efficacy of people's natural instincts to mitigate risk in response to the pandemic. 


\section{References}

(2020). Operation of and demand for public transport during covid-19: Descriptive evidence from sierra leone.

Africa, U. (2020). Beating covid-19 with solidarity. Medium.com.

Alsan, M., L. Braghieri, S. Eichmeyer, M. J. Kim, S. Stantcheva, D. Y. Yang, et al. (2020). Civil liberties in times of crisis. NBER Working Paper (27972).

Alsan, M., S. Stantcheva, D. Yang, and D. Cutler (2020, 06). Disparities in Coronavirus 2019 Reported Incidence, Knowledge, and Behavior Among US Adults. JAMA Network Open 3(6), e2012403-e2012403.

Amare, M., K. A. Abay, L. Tiberti, and J. Chamberlin (2020). Impacts of Covid-19 on food security: panel data evidence from Nigeria, Volume 1956. Intl Food Policy Res Inst.

Asiamah, N., F. F. Opuni, E. Mends-Brew, S. W. Mensah, H. K. Mensah, and F. Quansah (2020). Short-term changes in behaviors resulting from covid-19-related social isolation and their influences on mental health. Community Mental Health Journal.

Badoe, E. (2017). A critical review of child abuse and its management in africa. African journal of emergency medicine 7, S32-S35.

Bank, W. (2020). World development indicators.

Cairncross, S., K. Shordt, S. Zacharia, and B. K. Govindan (2005). What causes sustainable changes in hygiene behaviour? a cross-sectional study from kerala, india. Social science $\&$ medicine 61(10), 2212-2220.

Castex, G., E. Dechter, and M. Lorca (2020a). Covid-19: Cross-country heterogeneity in effectiveness of non-pharmaceutical interventions. Covid Economics 14, 175-199.

Castex, G., E. Dechter, and M. Lorca (2020b). Covid-19: The impact of social distancing policies, cross-country analysis. Economics of disasters and climate change, 1-25.

Chiplunkar, G. and S. Das (2020). Political institutions and policy responses during a crisis. Available at SSRN 3629397.

Cowling, B. J. and A. E. Aiello (2020). Public health measures to slow community spread of coronavirus disease 2019. The Journal of infectious diseases 221(11), 1749-1751.

Derksen, L., J. Kerwin, N. Ordaz Reynoso, and O. Sterck (2020). Appointments versus commitments: Overcoming self-control problems in preventive health.

Dupas, P. (2011a). Do teenagers respond to hiv risk information? evidence from a field experiment in kenya. American Economic Journal: Applied Economics 3(1), 1-34.

Dupas, P. (2011b). Health behavior in developing countries. Annu. Rev. Econ. 3(1), 425-449. 
Eikenberry, S. E., M. Mancuso, E. Iboi, T. Phan, K. Eikenberry, Y. Kuang, E. Kostelich, and A. B. Gumel (2020). To mask or not to mask: Modeling the potential for face mask use by the general public to curtail the covid-19 pandemic. Infectious Disease Modelling.

Erokhin, V. and T. Gao (2020). Impacts of covid-19 on trade and economic aspects of food security: Evidence from 45 developing countries. International journal of environmental research and public health 17(16), 5775 .

for Africa, U. N. E. C. (2020). Covid-19 in africa: protecting lives and economies.

for Strategic Studies, A. C. (2020, Apr). African Adaptations to the COVID-19 Response.

Gandhi, M., C. Beyrer, and E. Goosby (2020). Masks do more than protect others during covid-19: reducing the inoculum of sars-cov-2 to protect the wearer. Journal of general internal medicine 35(10), 3063-3066.

Geldsetzer, P. (2020). Knowledge and perceptions of covid-19 among the general public in the united states and the united kingdom: A cross-sectional online survey. Annals of internal medicine.

Goldberg, P. K. and T. Reed (2020). The effects of the coronavirus pandemic in emerging market and developing economies an optimistic preliminary account. Brooking Papers on Economic Activity 6, 1.

GRID3 (2020). Sierra leone is fighting smart against covid-19. Blog Post.

Haushofer, J. and C. J. E. Metcalf (2020). Which interventions work best in a pandemic? Science 368(6495), 1063-1065.

Jain, R., J. Budlender, R. Zizzamia, and I. Bassier (2020). The labor market and poverty impacts of covid-19 in south africa.

Jalan, J. and E. Somanathan (2008). The importance of being informed: Experimental evidence on demand for environmental quality. Journal of development Economics 87(1), $14-28$.

Josephson, A., T. Kilic, and J. D. Michler (2020). Socioeconomic impacts of covid-19 in four african countries.

Kao, K., E. Lust, B. Dulani, K. E. Ferree, A. S. Harris, and E. Metheney (2020). The abcs of covid-19 prevention in malawi: Authority, benefits, and costs of compliance. World development 137, 105167.

Karing, A. (2020). Operation of and demand for public transport during covid-19: Descriptive evidence from sierra leone.

Kerwin, J. T. (2020). The effect of hiv infection risk beliefs on sexual behavior: Scared straight or scared to death?

Kerwin, J. T. and N. O. Reynoso (2020). You know what i know: Interviewer knowledge effects in subjective expectation elicitation. Demography. 
Kremer, M., J. Leino, E. Miguel, and A. P. Zwane (2007). Spring cleaning: a randomized evaluation of source water quality improvement. Quarterly Journal of Economics 4(2), 09-30.

Liu, Y., R. M. Eggo, and A. J. Kucharski (2020). Secondary attack rate and superspreading events for sars-cov-2. The Lancet 395(10227), e47.

Lo, N. C., A. Lowe, and E. Bendavid (2016). Abstinence funding was not associated with reductions in hiv risk behavior in sub-saharan africa. Health affairs 35(5), 856-863.

Lone, S. A. and A. Ahmad (2020). Covid-19 pandemic-an african perspective. Emerging Microbes 85 Infections, 1-28.

Lucas, A. M. (2010, April). Malaria eradication and educational attainment: Evidence from paraguay and sri lanka. American Economic Journal: Applied Economics 2(2), 46-71.

Lucas, A. M. and N. L. Wilson (2018). Can at-scale drug provision improve the health of the targeted in sub-saharan africa? American Journal of Health Economics 4(3), 358-382.

Lyu, W. and G. L. Wehby (2020). Community use of face masks and covid-19: Evidence from a natural experiment of state mandates in the us: Study examines impact on covid19 growth rates associated with state government mandates requiring face mask use in public. Health affairs 39(8), 1419-1425.

Madajewicz, M., A. Pfaff, A. van Geen, J. Graziano, I. Hussein, H. Momotaj, R. Sylvi, and H. Ahsan (2007, November). Can Information Alone Change Behavior? Response To Arsenic Contamination Of Groundwater In Bangladesh. Journal of Development Economics $84(2), 731-754$.

Mahmud, M. and E. Riley (2020). Household response to an extreme shock: Evidence on the immediate impact of the covid-19 lockdown on economic outcomes and well-being in rural uganda.

Marois, G., R. Muttarak, and S. Scherbov (2020). Assessing the potential impact of covid-19 on life expectancy. Plos one 15(9), e0238678.

Masina, L. (2020, Mar). Malawi orders political opposition to halt coronavirus education campaigns. VOANews.

Meinck, F., L. D. Cluver, M. E. Boyes, and E. L. Mhlongo (2015). Risk and protective factors for physical and sexual abuse of children and adolescents in africa: A review and implications for practice. Trauma, Violence, \& Abuse 16(1), 81-107.

Murray, E. J. (2020). Epidemiology's time of need: Covid-19 calls for epidemic-related economics. Journal of Economic Perspectives 34(4), 105-20.

Organization, W. H. et al. (2016). Global health observatory (gho) data. 2020. Hospital Beds (per 10,000 population). WHO, Geneva. 
Osseni, I. A. (2020). Covid-19 pandemic in sub-saharan africa: preparedness, response, and hidden potentials. Tropical medicine and health 48(1), 1-3.

Oster, E. (2012). Hiv and sexual behavior change: Why not africa? Journal of health economics 31(1), 35-49.

Rannan-Eliya, R. P., N. Wijemunige, J. Gunawardana, S. N. Amarasinghe, I. Sivagnanam, S. Fonseka, Y. Kapuge, and C. P. Sigera (0). Increased intensity of pcr testing reduced covid-19 transmission within countries during the first pandemic wave. Health Affairs 0(0), 10.1377/hlthaff.2020.01409. PMID: 33264048.

Squires, M. (2020). Kinship taxation as an impediment to growth: experimental evidence from kenyan and tanzanian microenterprises. Working paper.

Zheng, Q., F. K. Jones, S. V. Leavitt, L. Ung, A. B. Labrique, D. H. Peters, E. C. Lee, and A. S. Azman (2020). Hit-covid, a global database tracking public health interventions to covid-19. Scientific data 7(1), 1-8. 
Figure 1: Time Trend of Symptom Knowledge
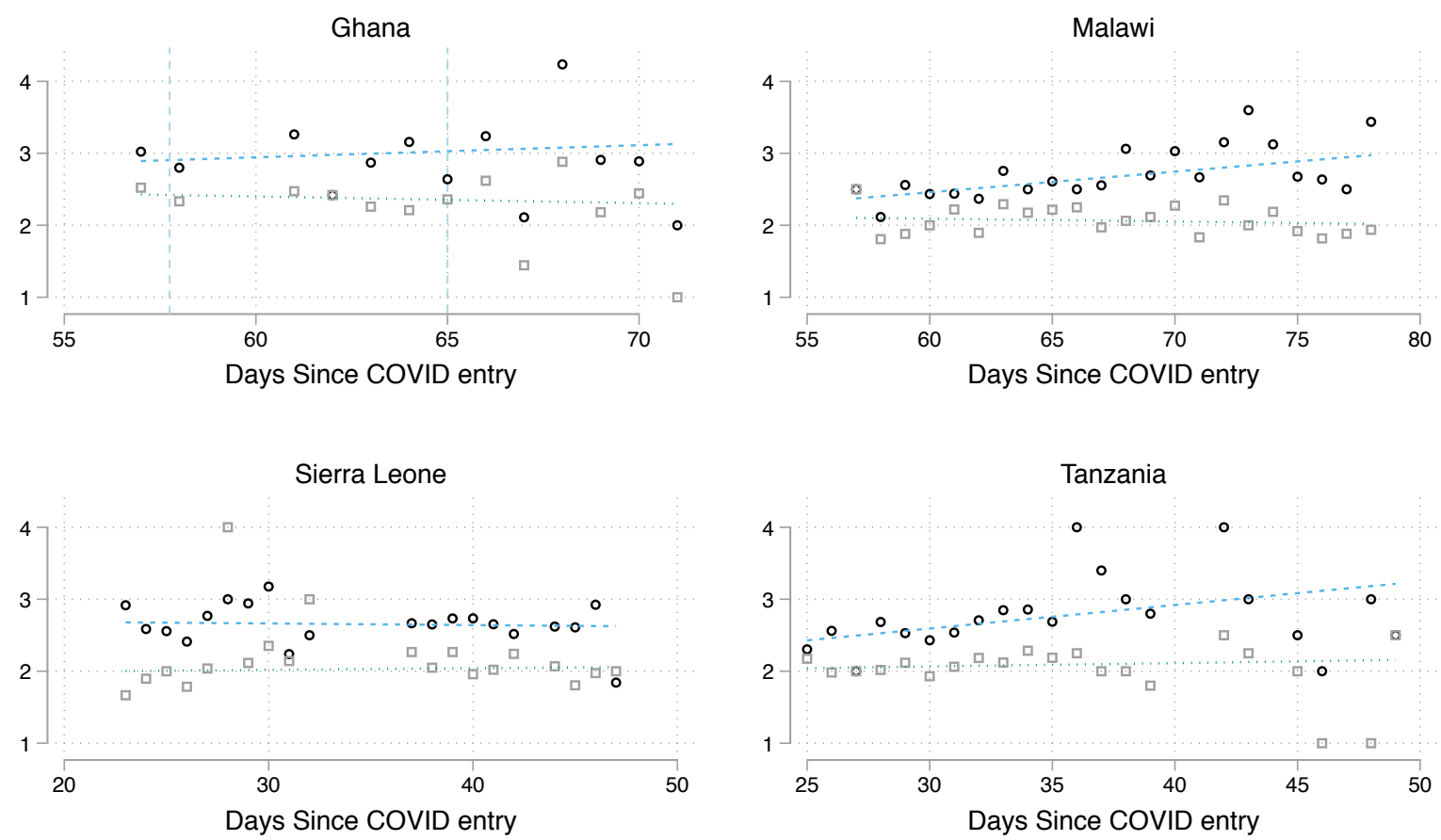

- \# of correct symptoms $\square$ \# of correct transmission

... \# of correct symptoms …. \# of correct transmission

Notes: Above are the time trends of the primary knowledge variables disaggregated by country, weighted by the number of interviews in the country per day. In Ghana, Sierra Leone, and Tanzania there is no statistically significant time trend of symptom or transmission knowledge. In Malawi, there is a weak positive time trend for symptom knowledge $(\mathrm{p}=0.052)$ but not transmission knowledge. 
Table 1: Country \& Dataset Descriptions

Panel A: COVID experiences

First COVID case

Lockdown

Scope of Closures

Nationwide Mask

Mandate

Est. Cases (Nov 2)

Cases Per Million Pop
(1)

Ghana
(2) Malawi

March 12

March 16-May 20

All public Lockdown was gatherings banned, churches and schools closed announced but challenged in court and did not occur
(3) Sierra Leone March 30 March 16 Tanzania May 2-June 24 March 17-June 1

$\begin{array}{cc}2 \text { 3-day } & \text { Schools closed, } \\ \text { lockdown; } & \text { ban on mass } \\ \text { businesses } & \text { public } \\ \text { hurches/schools } & \text { gatherings, } \\ \text { otherwise } \\ \text { limited in } \\ & \text { scope. }\end{array}$

April 24

August 7

48,200

1,551
5,933

310
April 24

2,366

297

\section{Not Enacted}

(See notes)

509 (see notes)

9 (see notes)

Panel B: COVID Survey Statistics

\begin{tabular}{|c|c|c|c|c|}
\hline Geographic Scope & 7 regions & Zomba & Freetown & $\begin{array}{c}\text { Dar Es Salaam } \\
\text { and Dodoma } \\
\text { regions }\end{array}$ \\
\hline Respondent type & Educators & $\begin{array}{l}\text { Men who } \\
\text { frequent bars }\end{array}$ & Travelers & $\begin{array}{l}\text { Microenterprise } \\
\text { owners }\end{array}$ \\
\hline $\begin{array}{l}\text { Data Collection } \\
\text { Period }\end{array}$ & May 7-May 22 & $\begin{array}{c}\text { May 29-June } \\
19\end{array}$ & $\begin{array}{c}\text { April } 22-30, \\
\text { May } 6-16\end{array}$ & April 10-May 4 \\
\hline Total N & 362 & 1232 & 633 & 557 \\
\hline Survey Response Rate & 0.88 & 0.46 & 0.79 & 0.93 \\
\hline
\end{tabular}

Notes: In Tanzania, the mask mandate nationwide is only a recommendation and not a requirement. Local officials in Dar es Salaam ordered residents to wear face masks starting April 18. Tanzania stopped reporting virus cases and deaths May 8. Data on coronavirus caseloads and deaths are from the Kaiser Family Foundation database as of November 2, 2020.The Ghana lockdown was partially lifted April 16. 
Table 2: Sample Statistics

\begin{tabular}{lcccccc}
\hline \hline & $\begin{array}{c}(1) \\
\text { Ghana }\end{array}$ & $\begin{array}{c}(2) \\
\text { Malawi }\end{array}$ & $\begin{array}{c}(3) \\
\text { Sierra } \\
\text { Leone }\end{array}$ & $\begin{array}{c}(4) \\
\text { Tanzania }\end{array}$ & $\begin{array}{c}(5) \\
\text { Average }\end{array}$ & $\begin{array}{c}(6) \\
\text { PValue } \\
\text { Joint } \\
\text { Eq }\end{array}$ \\
\hline Age & 34.8 & 35.1 & 30.5 & 37.0 & 34.2 & 0.00 \\
Male & 0.82 & 1.00 & 0.66 & 0.56 & 0.75 & 0.00 \\
Has children & 0.86 & 0.93 & 0.94 & 0.87 & 0.91 & 0.00 \\
Rural & 0.76 & 0 & 0 & 0.40 & 0.23 & 0.00 \\
No schooling & 0.00 & 0.00 & 0.02 & 0.02 & 0.01 & 0.02 \\
Some Schooling & 0.00 & 0.20 & 0.17 & 0.83 & 0.35 & 0.00 \\
Secondary or Higher & 1.0 & 0.79 & 0.82 & 0.15 & 0.63 & 0.00 \\
\hline Observations & 362 & 563 & 633 & 557 & 2115 & \\
\hline \hline
\end{tabular}

Notes: Above are averages of select variables aggregated for each country. Missing observations for a given variable are not included. Column 6 contains the p-value of the joint test of equality of the averages by country. ${ }^{*} p<0.10,{ }^{* *} p<0.05, * * * p<0.01$ 
Table 3: Summaries of Main Outcome Measures by Country

\begin{tabular}{|c|c|c|c|c|c|c|}
\hline Panel A: Transmission Knowledge & Ghana & Malawi & $\begin{array}{l}\text { Sierra } \\
\text { Leone }\end{array}$ & Tanzania & Total & $\begin{array}{c}\text { PValue } \\
\text { Joint } \\
\text { Eq } \\
(6)\end{array}$ \\
\hline No transmission knowledge & 0.00 & 0.01 & 0.02 & 0.02 & 0.01 & 0.09 \\
\hline \#Correct transmission mechanisms & 2.4 & 2.1 & 2.0 & 2.1 & 2.1 & 0.66 \\
\hline Airborne cough & 0.84 & 0.96 & 0.82 & 0.79 & 0.85 & 0.00 \\
\hline Touching others & 0.80 & 0.71 & 0.77 & 0.82 & 0.77 & 0.00 \\
\hline Touching surfaces & 0.64 & 0.37 & 0.36 & 0.38 & 0.42 & 0.63 \\
\hline Asymptomatic people & 0.10 & 0.03 & 0.08 & 0.08 & 0.07 & 0.00 \\
\hline \multicolumn{7}{|l|}{ Panel B: Symptom Knowledge } \\
\hline Stated no knowledge of symptoms & 0.01 & 0.01 & 0.02 & 0.05 & 0.02 & 0.00 \\
\hline \# Correct symptoms listed & 3.2 & 2.8 & 3.1 & 2.9 & 3.0 & 0.51 \\
\hline Coughing & 0.90 & 0.79 & 0.77 & 0.709 & 0.78 & 0.01 \\
\hline Fever & 0.74 & 0.80 & 0.73 & 0.618 & 0.72 & 0.00 \\
\hline Sneezing & 0.57 & 0.63 & 0.74 & 0.44 & 0.60 & 0.00 \\
\hline Difficulty breathing & 0.38 & 0.60 & 0.39 & 0.46 & 0.46 & 0.00 \\
\hline Headache & 0.42 & 0.00 & 0.28 & 0.43 & 0.27 & 0.00 \\
\hline Sore throat & 0.32 & 0.01 & 0.26 & 0.13 & 0.17 & 0.00 \\
\hline Fatigue & 0.17 & 0.02 & 0.15 & 0.24 & 0.14 & 0.00 \\
\hline Loss of smell & 0.04 & 0.32 & 0.04 & 0.01 & 0.10 & 0.00 \\
\hline Loss of taste & 0.03 & 0.146 & 0.04 & 0.00 & 0.06 & 0.00 \\
\hline \multicolumn{7}{|l|}{ Panel C: Protective Measures } \\
\hline No protective measures & 0.00 & 0.13 & 0.00 & 0.00 & 0.04 & 0.00 \\
\hline \# Protective measures taken & 3.4 & 2.1 & 3.4 & 2.4 & 2.8 & 0.00 \\
\hline \# Effective protective measures taken & 3.0 & 1.7 & 3.0 & 1.7 & 2.3 & 0.00 \\
\hline Wearing mask & 0.78 & 0.30 & 0.82 & 0.18 & 0.49 & 0.00 \\
\hline Hand washing & 0.85 & 0.82 & 0.85 & 0.86 & 0.84 & 0.28 \\
\hline Hand sanitizer & 0.66 & 0.00 & 0.61 & 0.18 & 0.33 & 0.00 \\
\hline Not shaking hands & 0.25 & 0.48 & 0.35 & .60 & 0.44 & 0.00 \\
\hline Not sharing foods & 0.04 & 0.01 & 0.00 & 0.01 & 0.01 & 0.11 \\
\hline Not affected & 0.08 & 0.11 & - & 0.18 & 0.14 & 0.00 \\
\hline \multicolumn{7}{|l|}{ Panel D: Social Distancing } \\
\hline Decreased social contacts & 0.74 & 0.75 & 0.66 & 0.52 & 0.66 & 0.00 \\
\hline Contact non-household? & 0.72 & 1.00 & 1.00 & 1.00 & 0.95 & 0.00 \\
\hline \# Places In Last Week & 1.61 & 5.47 & 1.72 & 3.18 & 3.11 & 0.00 \\
\hline Children Had Contact Outside HH & 0.48 & 0.79 & 0.50 & 0.60 & 0.60 & 0.00 \\
\hline Observations & 362 & 563 & 633 & 557 & 2115 & \\
\hline
\end{tabular}

Notes: Above are averages of select variables aggregated for each country. Missing observations for a given variable are not included. Whether children living in the household had contacts with others is among the sample that has children living in their household. Due to an omission, how respondents were affected by the pandemic were not asked in Sierra Leone. Column 6 contains the p-value of the joint test of equality of the averages by country. Correct transmission is defined as reporting contracting the coronavirus from others, through air; by touching others; from touching contaminated surfaces, and asymptomatic infections. Correct symptoms are defined as coughing, fever, fatigue, difficulty breathing, loss of smell/taste, headache, and sore throat. 
Table 4: Reports of Ways Affected by Pandemic

\begin{tabular}{lccccc}
\hline \hline & $(1)$ & $(2)$ & $(3)$ & $(4)$ & $(5)$ \\
& Ghana & Malawi & Tanzania & $\begin{array}{c}(4) \\
\text { Average }\end{array}$ & PValue Joint Eq \\
\hline Reduction in income/resources & 0.39 & 0.75 & 0.40 & 0.54 & 0.00 \\
Stress & 0.65 & 0.45 & 0.44 & 0.49 & 0.00 \\
Children home from school & 0.44 & 0.47 & 0.25 & 0.38 & 0.41 \\
Reduction in food & 0.17 & 0.11 & 0.05 & 0.10 & 0.0 \\
Household infected & 0.01 & 0.09 & 0.00 & 0.04 & 0.0 \\
Increase in household size & 0.09 & 0.02 & 0.04 & 0.04 & 0.0 \\
Less monetary transfers & 0.00 & 0.08 & 0.00 & 0.03 & 0.32 \\
Sent more transfers & 0.07 & 0.00 & 0.04 & 0.03 & 0.0 \\
Increase on phone/internet & 0.07 & 0.00 & 0.01 & 0.02 & 0.0 \\
Decrease in household size & 0.01 & 0.02 & 0.02 & 0.02 & 0.0 \\
More monetary transfers & 0.00 & 0.00 & 0.01 & 0.08 & 0.32 \\
Household death & 0.01 & 0.01 & 0.00 & 0.01 & 0.45 \\
Self-infected & 0.01 & 0.01 & 0.00 & 0.01 & 0.99 \\
\hline Observations & 278 & 563 & 557 & 1398 & \\
\hline \hline
\end{tabular}

Notes: Above are averages of select variables aggregated for each country. Missing observations for a given variable are not included. Due to an omission these questions were not asked in Sierra Leone. Column 5 contains the p-value of the joint test of equality of the averages by country. 


\section{Table 5: Correlates of Knowledge and Behavior}

\begin{tabular}{|c|c|c|c|c|}
\hline & $\begin{array}{c}\text { (1) } \\
\text { \# Correct Symptoms }\end{array}$ & $\begin{array}{c}(2) \\
\text { \# Correct Transmission }\end{array}$ & $\begin{array}{c}(3) \\
\text { \# Effective } \\
\text { Protective Measures }\end{array}$ & $\begin{array}{c}(4) \\
\text { \# Social Contacts }\end{array}$ \\
\hline \multicolumn{5}{|c|}{ Demographic Variables } \\
\hline Male & $\begin{array}{l}-0.107 \\
(0.066)\end{array}$ & $\begin{array}{c}0.063 \\
(0.043)\end{array}$ & $\begin{array}{l}0.110^{*} \\
(0.061)\end{array}$ & $\begin{array}{c}0.267^{* * *} \\
(0.088)\end{array}$ \\
\hline Age & $\begin{array}{l}0.023^{*} \\
(0.013)\end{array}$ & $\begin{array}{c}0.007 \\
(0.010)\end{array}$ & $\begin{array}{c}0.014 \\
(0.013)\end{array}$ & $\begin{array}{c}0.018 \\
(0.021)\end{array}$ \\
\hline Children in $\mathrm{HH}$ & $\begin{array}{l}-0.049 \\
(0.089)\end{array}$ & $\begin{array}{l}-0.014 \\
(0.060)\end{array}$ & $\begin{array}{c}0.212^{* *} \\
(0.085)\end{array}$ & $\begin{array}{c}0.055 \\
(0.125)\end{array}$ \\
\hline Some Schooling & $\begin{array}{l}0.312^{*} \\
(0.186)\end{array}$ & $\begin{array}{c}0.390^{* *} \\
(0.168)\end{array}$ & $\begin{array}{c}0.050 \\
(0.216)\end{array}$ & $\begin{array}{c}0.436 \\
(0.422)\end{array}$ \\
\hline Secondary or Higher & $\begin{array}{c}0.757^{* * *} \\
(0.188)\end{array}$ & $\begin{array}{c}0.634^{* * *} \\
(0.171)\end{array}$ & $\begin{array}{c}0.243 \\
(0.219)\end{array}$ & $\begin{array}{c}0.431 \\
(0.420)\end{array}$ \\
\hline Rural & $\begin{array}{l}-0.111 \\
(0.089)\end{array}$ & $\begin{array}{l}-0.078 \\
(0.058)\end{array}$ & $\begin{array}{c}-0.072 \\
(0.071)\end{array}$ & $\begin{array}{c}-0.146 \\
(0.142)\end{array}$ \\
\hline \multicolumn{5}{|l|}{ Country Dummies } \\
\hline Malawi & $\begin{array}{l}-0.185 \\
(0.120)\end{array}$ & $\begin{array}{c}-0.299^{* * *} \\
(0.080)\end{array}$ & $\begin{array}{c}-1.188^{* * *} \\
(0.103)\end{array}$ & $\begin{array}{c}3.777^{* * *} \\
(0.172)\end{array}$ \\
\hline Sierra Leone & $\begin{array}{c}-0.214^{*} \\
(0.124)\end{array}$ & $\begin{array}{c}-0.272^{* * *} \\
(0.080)\end{array}$ & $\begin{array}{c}0.055 \\
(0.101)\end{array}$ & $\begin{array}{c}0.123 \\
(0.156)\end{array}$ \\
\hline Tanzania & $\begin{array}{l}-0.062 \\
(0.125)\end{array}$ & $\begin{array}{l}-0.105 \\
(0.082)\end{array}$ & $\begin{array}{c}-0.839^{* * *} \\
(0.108)\end{array}$ & $\begin{array}{c}2.089^{* * *} \\
(0.186)\end{array}$ \\
\hline Observations & 1,991 & 1,991 & 1,991 & 1,991 \\
\hline$R^{2}$ & 0.04 & 0.04 & 0.21 & 0.48 \\
\hline Mean Dep. & 2.69 & 2.11 & 2.71 & 3.17 \\
\hline Country Jointly Zero & 0.28 & 0.00 & 0.00 & 0.00 \\
\hline Education Jointly Zero & 0.00 & 0.00 & 0.03 & 0.58 \\
\hline
\end{tabular}

Notes: The omitted category for education is those with no schooling. The omitted country is Ghana. Individuals with missing control variables have their value set equal to the mean for their country with a dummy variable to mark the imputation. Robust standard errors correcting for heteroskedasticity in parenthesis. "Country Jointly Zero" presents the p-value on the null that all country dummies are jointly equal to zero. "Education Jointly Zero" presents the p-value on the null that all education dummies are jointly equal to zero. ${ }^{*} p<0.10,{ }^{* *} p<0.05,{ }^{* * *} p<0.01$ 
Table 6: Correlates of Protective Measures Taken

\begin{tabular}{|c|c|c|}
\hline & $\begin{array}{c}(1) \\
\text { \# Effective } \\
\text { Protective Measures }\end{array}$ & $\begin{array}{c}(2) \\
\text { \# Effective } \\
\text { Protective Measures }\end{array}$ \\
\hline \# Correct Symptoms Listed & $\begin{array}{c}0.230^{* * *} \\
(0.020)\end{array}$ & $\begin{array}{c}0.230^{* * *} \\
(0.021)\end{array}$ \\
\hline \# Correct Transmission Mechanisms & $\begin{array}{c}0.400^{* * *} \\
(0.030)\end{array}$ & $\begin{array}{c}0.398^{* * *} \\
(0.031)\end{array}$ \\
\hline Male & & $\begin{array}{l}0.092^{*} \\
(0.055)\end{array}$ \\
\hline Age & & $\begin{array}{c}0.010 \\
(0.012)\end{array}$ \\
\hline Rural & & $\begin{array}{l}-0.013 \\
(0.064)\end{array}$ \\
\hline Some Schooling & & $\begin{array}{l}-0.168 \\
(0.190)\end{array}$ \\
\hline Secondary or Higher & & $\begin{array}{l}-0.179 \\
(0.194)\end{array}$ \\
\hline Observations & 1,991 & 1,991 \\
\hline$R^{2}$ & 0.35 & 0.35 \\
\hline Mean Dep. & 2.71 & 2.71 \\
\hline
\end{tabular}

Notes: All regressions include a country fixed effect. Column 2: The omitted educational category is those with no schooling. Individuals with missing control variables have their value set equal to the mean for their country with a dummy variable to mark the imputation. Robust standard errors to correct for heteroskedasticity in parenthesis. ${ }^{*} p<0.10,{ }^{* *} p<0.05,{ }^{* * *} p<0.01$ 


\section{Table 7: Correlates of \# Contacts}

\begin{tabular}{lccc}
\hline & $(1)$ & $(2)$ & $(3)$ \\
& \# Contacts & \# Contacts & \# Formal Contacts \\
\hline \# Correct Symptoms Listed & 0.030 & -0.007 & -0.006 \\
& $(0.035)$ & $(0.035)$ & $(0.018)$ \\
\# Correct Transmission Mechanisms & $0.258^{* * *}$ & $0.191^{* * *}$ & 0.037 \\
& $(0.050)$ & $(0.052)$ & $(0.027)$ \\
\#Protective Measures (excluding social distancing) & & $0.189^{* * *}$ & $0.058^{* * *}$ \\
& & $(0.040)$ & $(0.021)$ \\
Male & $0.249^{* * *}$ & $0.245^{* * *}$ & $0.187^{* * *}$ \\
& $(0.086)$ & $(0.086)$ & $(0.043)$ \\
Age & 0.017 & 0.015 & $0.027^{* * *}$ \\
& $(0.021)$ & $(0.021)$ & $(0.010)$ \\
Rural & -0.122 & -0.100 & $0.363^{* * *}$ \\
Some Schooling & $(0.142)$ & $(0.142)$ & $(0.074)$ \\
& 0.329 & 0.346 & 0.267 \\
Secondary or Higher & $(0.414)$ & $(0.406)$ & $(0.214)$ \\
& 0.247 & 0.278 & 0.226 \\
Observations & $(0.413)$ & $(0.405)$ & $(0.213)$ \\
$R^{2}$ & 1,991 & 1,991 & 1,991 \\
Mean Dep. & 0.49 & 0.50 & 0.53 \\
\hline
\end{tabular}

Notes: All regressions include a country fixed effect. Individuals with missing control variables have their value set equal to the mean for their country with a dummy variable to mark the imputation. Column 3: Number of formal contacts includes contacts at houses of worship, events such as wedding or funerals, meetings, and meals at restaurants. Robust standard errors to correct for heteroskedasticity in parenthesis. ${ }^{*} p<0.10,{ }^{* *} p<0.05,{ }^{* * *} p<0.01$ 


\section{A Appendix A}

Below are the list of questions asked of respondents in each country. Questions were translated into local languages as appropriate.

1. Consider your household to be individuals who normally live and eat their meals together. In the past 7 days, have you or any household member come within 2 meters of other individuals who are not part of your household?
(a) Yes
(b) No (if no, skip to Question 3)

2. Where have you or any other household members come within 2 meters of other individual(s) not in your household? Do not prompt, tick all that respondent mentions.

(a) Market or a trading center or mall or supermarket

(b) Home of a friend or non-household family member

(c) Food distribution location

(d) Ate/drank at a Restaurant/bar/shop/hotel

(e) Getting takeaway from a restaurant/bar/shop/hotel

(f) During employment activities, e.g. working near someone.

(g) Religious or other worship services (including bible study and choir)

(h) Wedding or funeral or anniversary

(i) Non-religious community, political or other group meeting

(j) Minibus (Trotro) or Taxi

(k) Okada (Motor cycle taxi)

(l) Communal toilet or bath

(m) Other (Specify) 
3. In the past 7 days, have the children or youth in your household played or socialized in close physical proximity with children outside of your household?

(a) I do not have any children or youth in my household.

(b) Yes

(c) No

4. Can you tell me what you know about the symptoms of COVID? Do not prompt, tick all that respondent mentions.

(a) I don't know any symptoms (if select this cannot select anything else)

(b) Coughing

(c) Fever

(d) Sneezing

(e) Fatigue

(f) Difficulty breathing

(g) Loss of smell

(h) Loss of taste

(i) Headache

(j) Sore Throat

(k) Other (Specify)

5. Can you tell me what you know about how COVID is transmitted? Do not prompt, tick all that respondent mentions.

(a) I do not know how it's transmitted (if select this cannot select anything else)

(b) From other people coughing/breathing common air/inhaling germs

(c) Shaking hands/touching other people 
(d) Touching contaminated surfaces

(e) Even people who do not show symptoms might be infected

(f) Even people who do not show symptoms might be contagious

(g) Eating bad/spoiled/unripe food

(h) Witchcraft

(i) It only/primarily affects older people

(j) It only/primarily affects younger people

(k) Other(specify)

6. What are you doing to prevent an infection of the Covid-19? Do not prompt, tick all that respondent mentions.

(a) Nothing (if select this cannot select anything else)

(b) Increased hand washing

(c) Wearing a nose/face mask

(d) Not shaking hands

(e) Stay distanced from others

(f) Not eating unwashed food

(g) Not eating from a shared plate or drinking from shared cup

(h) Drinking clean water

(i) Praying

(j) Preventative medicine (traditional or otherwise)

(k) Eating more healthfully

(1) Using hand sanitizer

(m) Other (specify) 
7. How has Covid and any related restrictions affected you? Do not prompt, tick all that respondent mentions.

(a) No effect (if select this cannot select anything else)

(b) I am infected/believe to be infected

(c) Someone in my household is infected/believe to be infected

(d) Someone in my household died

(e) I am stressed, depressed, worried, and/or anxious

(f) Children home from school

(g) A reduction in household income or resources

(h) A reduction in food availability

(i) The size of my household has increased, e.g. migrants have returned or other kin now reside together

(j) The size of my household has decreased, e.g. kin have left to live elsewhere

(k) Spending more time on the phone/internet

(l) Receiving more monetary transfers

(m) Receiving fewer monetary transfers

(n) Sending more monetary transfers

(o) Sending fewer monetary transfers

(p) Other (specify) 
Appendix B 
Figure B1: Percent of Respondents Reporting Each Protective Measure

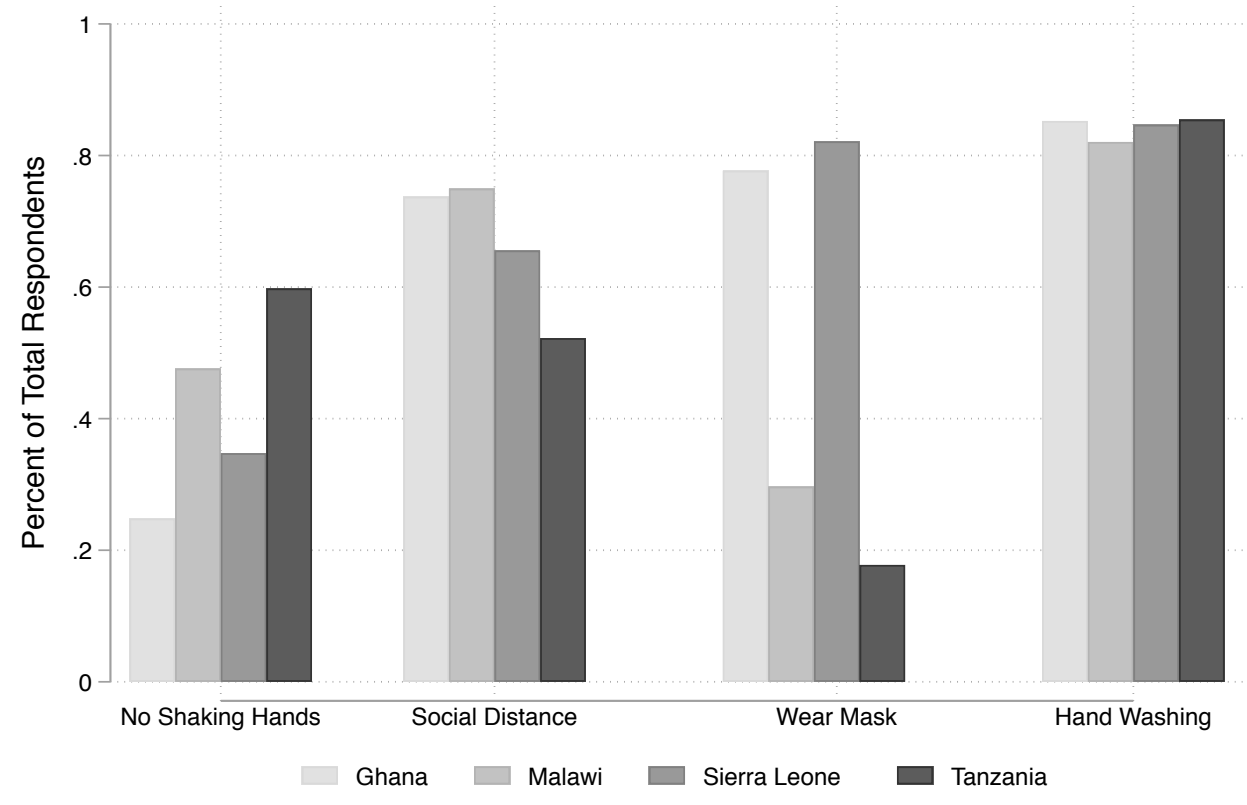

Notes: This bar chart shows the percent of respondents reporting the most commonly mentioned protective measures by country. 
Figure B2: Type of Social Contacts By Country

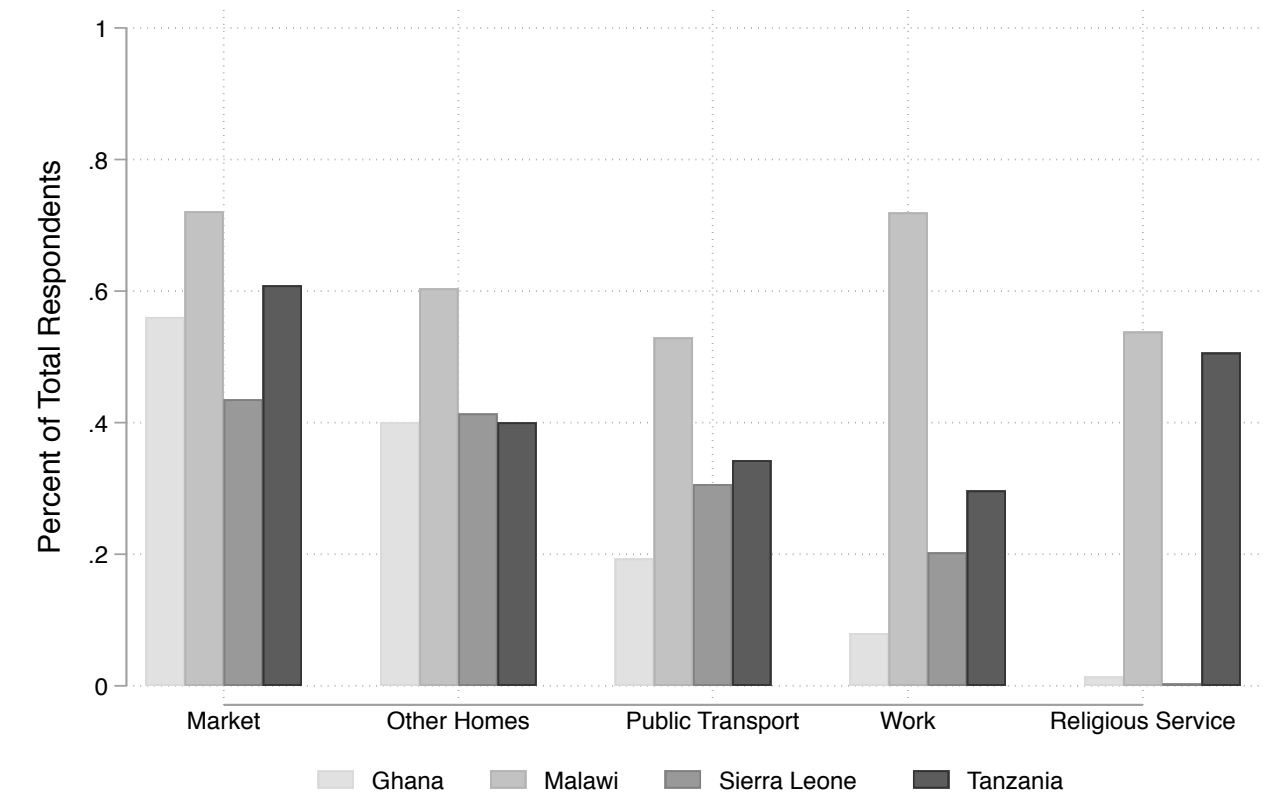

Notes: This bar chart shows where respondents reported close contact with a person outside of their household in the previous 6 days by country. 
Figure B3: Number of Preventive Behaviors By Number of Social Contacts

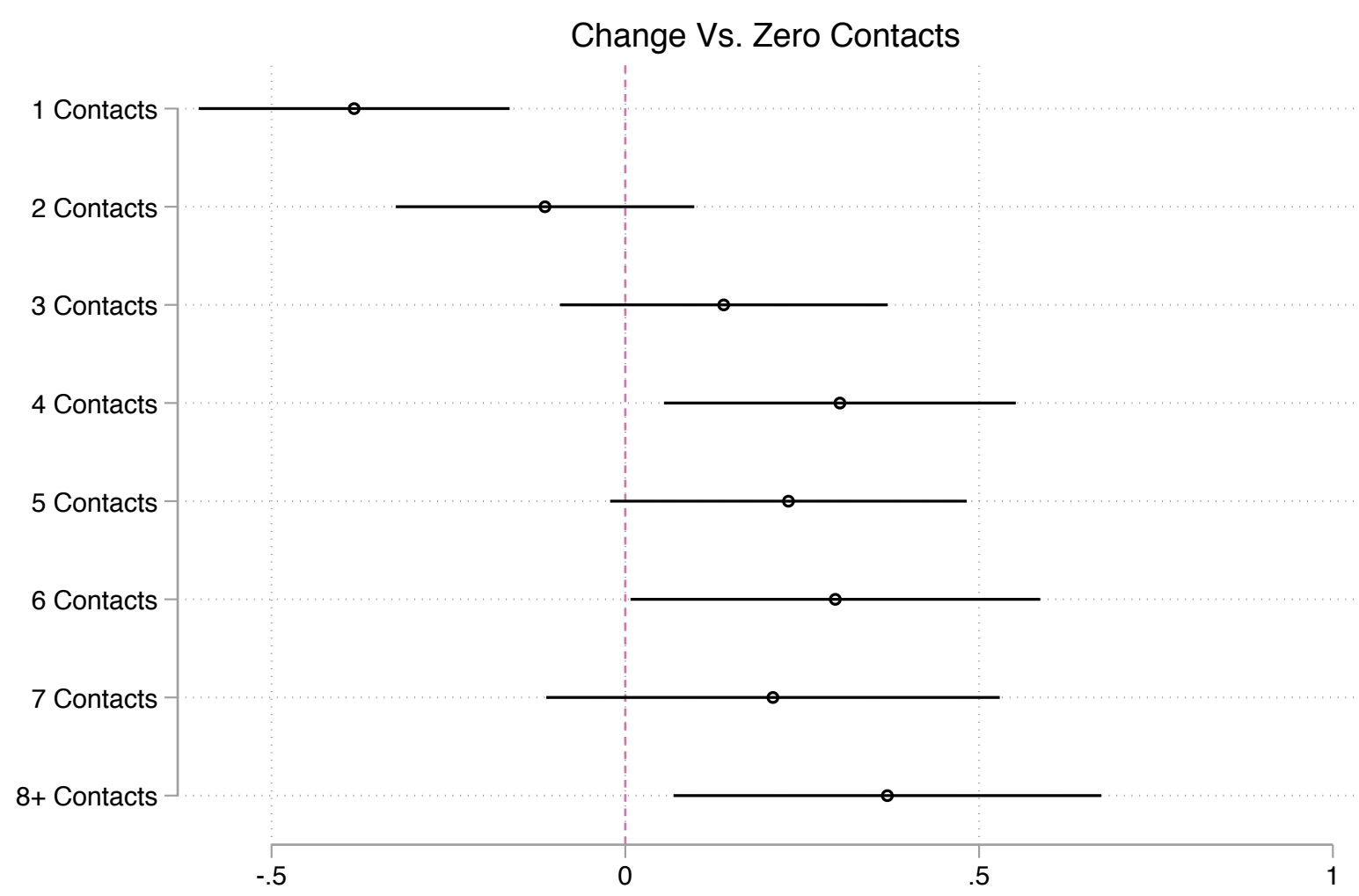

Notes: This coefficient plot displays the difference in number of protective activities that a respondent engages in disaggregated by the number of places that they report visiting in the past week. Coefficient estimates are based upon a regression that includes country fixed effects and the standard controls. 


\section{Figure B4: Likelihood of Mask Wearing By Number of Social Contacts}

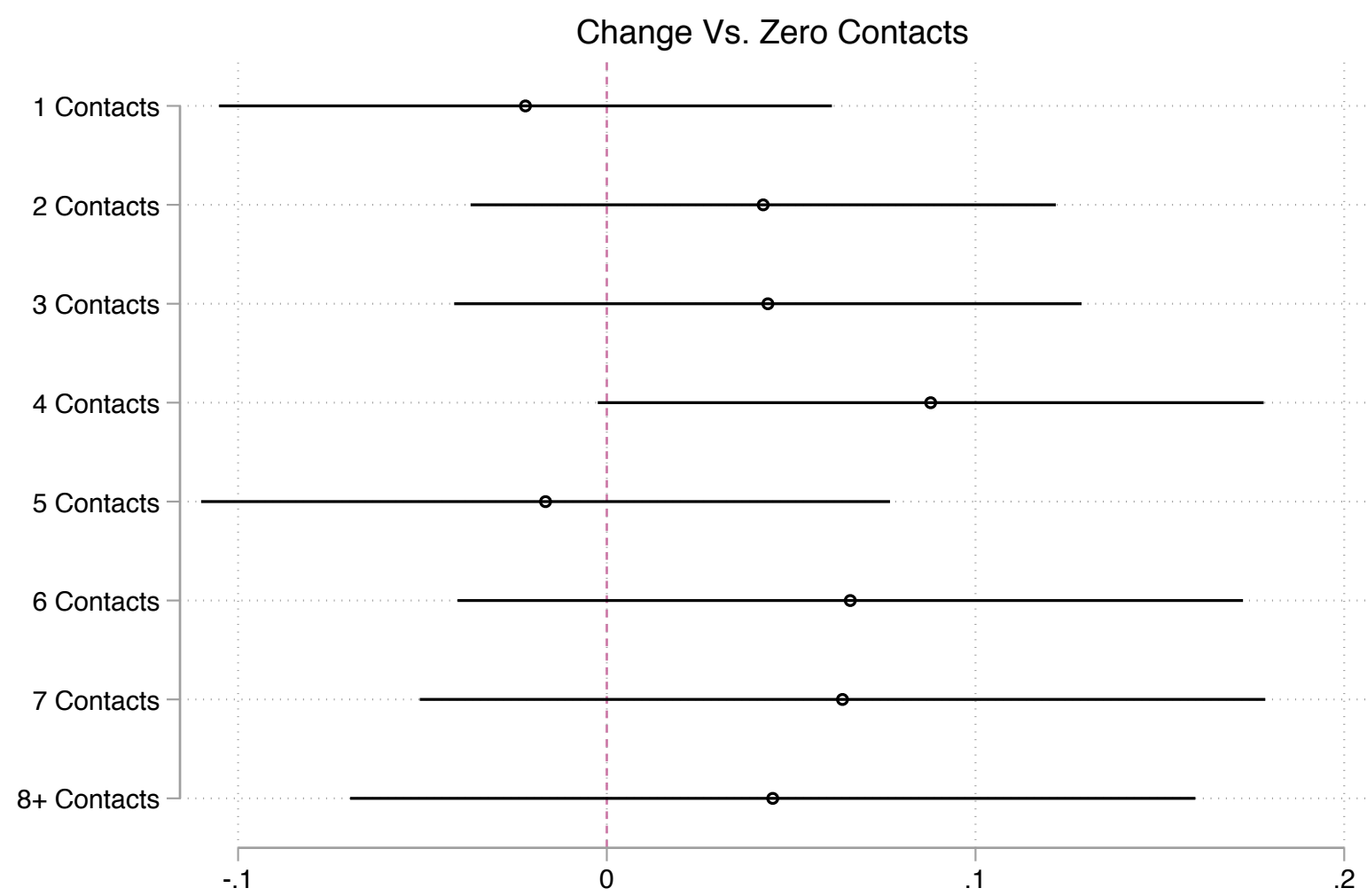

Notes: This coefficient plot displays the difference in number of protective activities that a respondent engages in disaggregated by the number of places that they report visiting in the past week. Coefficient estimates are based upon a regression that includes country fixed effects and the standard controls. 


\section{Table B1: Where Respondents Contacted Others in Past 6 Days}

\begin{tabular}{|c|c|c|c|c|c|c|}
\hline & $\begin{array}{c}\text { Ghana } \\
(1)\end{array}$ & $\begin{array}{l}\text { Malawi } \\
(2)\end{array}$ & $\begin{array}{c}\text { Sierra Leone } \\
(3) \\
\end{array}$ & $\begin{array}{c}\text { Tanzania } \\
(4)\end{array}$ & $\begin{array}{c}\text { Average } \\
\quad(5)\end{array}$ & $\begin{array}{l}\text { PValue of Equality } \\
(6)\end{array}$ \\
\hline \multicolumn{7}{|l|}{ Panel A: Contact Variables } \\
\hline Individual contact non-household & 0.72 & 1.0 & 1.0 & 1.0 & 0.95 & 1.0 \\
\hline \# Places In Last Week & 1.6 & 5.5 & 1.7 & 3.2 & 3.1 & 0.00 \\
\hline Children contact non-household & 0.48 & 0.79 & 0.50 & 0.60 & 0.60 & 0.00 \\
\hline \multicolumn{7}{|l|}{ Panel B: Contact Variables At Informal Gatherings } \\
\hline Contact at a market & 0.56 & 0.72 & 0.44 & 0.61 & 0.58 & 0.00 \\
\hline Contact in another home & 0.40 & 0.60 & 0.41 & 0.40 & 0.46 & 0.00 \\
\hline Contact on minibus & 0.19 & 0.53 & 0.31 & 0.34 & 0.36 & 0.00 \\
\hline Contact in communal toilet or bath & 0.04 & 0.41 & 0.02 & 0.12 & 0.16 & 0.00 \\
\hline Contact by takeout from bar, restaurant, etc. & 0.06 & 0.36 & 0.00 & 0.10 & 0.14 & 0.00 \\
\hline \multicolumn{7}{|l|}{ Panel C: Contact Variables At Formal Gatherings } \\
\hline Contact at work & 0.08 & 0.72 & 0.20 & 0.30 & 0.35 & 0.00 \\
\hline Contact at religious service/activity & 0.02 & 0.54 & 0.00 & $0.5^{6}$ & 0.28 & 0.00 \\
\hline Contact eating/drinking at bar, restaurant, etc. & 0.09 & 0.61 & 0.03 & 0.18 & 0.24 & 0.00 \\
\hline Contact at wedding, funeral, anniversary, etc. & 0.01 & 0.29 & 0.00 & 0.22 & 0.14 & 0.00 \\
\hline Contact at non-religious meeting & 0.01 & 0.15 & 0.01 & 0.07 & 0.06 & 0.00 \\
\hline Observations & 362 & 563 & 597 & 523 & 2045 & \\
\hline
\end{tabular}

Notes: Above are averages of select variables aggregated for each country. Missing observations for a given variable are not included. Children contact non-household only uses the sample of respondents with children in their household. Column 6 contains the p-value of the joint test of equality of the averages by country. 
Table B2: Affected by Stress

\begin{tabular}{lcccc}
\hline & $\begin{array}{c}\text { Did Not Report Stress } \\
(1)\end{array}$ & $\begin{array}{c}\text { Reported Stress } \\
(2)\end{array}$ & $\begin{array}{c}\text { Average } \\
(3)\end{array}$ & $\begin{array}{c}\text { PValue of Equality } \\
(4)\end{array}$ \\
\hline Number of Ways Affected & 0.98 & 2.23 & 1.58 & $0.00^{* * *}$ \\
Reduction in income/resources & 0.53 & 0.54 & 0.54 & 0.18 \\
Children home from school & 0.27 & 0.49 & 0.38 & $0.00^{* * *}$ \\
Self-infected & 0.01 & 0.00 & 0.01 & $0.067^{*}$ \\
Household infected & 0.07 & 0.01 & 0.04 & $0.00^{* * *}$ \\
Household death & 0.01 & 0.01 & 0.01 & 0.564 \\
Reduction in food & 0.12 & 0.08 & 0.10 & $0.00^{* * *}$ \\
Increase in household size & 0.04 & 0.04 & 0.04 & 0.937 \\
Decrease in household size & 0.01 & 0.02 & 0.02 & 0.966 \\
Increase on phone/internet & 0.01 & 0.02 & 0.07 & 0.621 \\
More monetary transfers & 0.01 & 0.01 & 0.01 & 0.906 \\
Less monetary transfers & 0.06 & 0.00 & 0.03 & 0.869 \\
Sent more transfers & 0.03 & 0.04 & 0.03 & 0.729 \\
\hline Observations & 717 & 681 & 1398 & \\
\hline
\end{tabular}

Notes: Above are averages of how respondents reported that they were affected by the pandemic, disaggregated by whether or not the respondent reported that they felt increased stress. 
Table B3: Regression Correlates of Detailed Protective Measures Taken

\begin{tabular}{|c|c|c|c|c|c|}
\hline & $\begin{array}{c}\text { (1) } \\
\text { Sanitize Hands }\end{array}$ & $\begin{array}{c}(2) \\
\text { Social Distancing }\end{array}$ & $\begin{array}{c}(3) \\
\text { Wash Hands }\end{array}$ & $\begin{array}{l}(4) \\
\text { Not Shaking } \\
\text { Hands }\end{array}$ & $\begin{array}{c}(5) \\
\text { Mask } \\
\text { Wearing }\end{array}$ \\
\hline \# Correct Symptoms Listed & $\begin{array}{c}0.034^{* * *} \\
(0.008)\end{array}$ & $\begin{array}{c}0.056^{* * *} \\
(0.009)\end{array}$ & $\begin{array}{c}0.019^{* *} \\
(0.008)\end{array}$ & $\begin{array}{c}0.077^{* * *} \\
(0.009)\end{array}$ & $\begin{array}{c}0.031^{* * *} \\
(0.008)\end{array}$ \\
\hline \# Correct Transmission Mechanisms & $\begin{array}{c}0.029^{* *} \\
(0.012)\end{array}$ & $\begin{array}{c}0.088^{* * *} \\
(0.014)\end{array}$ & $\begin{array}{c}0.067^{* * *} \\
(0.012)\end{array}$ & $\begin{array}{c}0.158^{* * *} \\
(0.014)\end{array}$ & $\begin{array}{c}0.030^{* *} \\
(0.013)\end{array}$ \\
\hline Male & $\begin{array}{l}-0.028 \\
(0.025)\end{array}$ & $\begin{array}{c}0.061^{* *} \\
(0.027)\end{array}$ & $\begin{array}{c}0.016 \\
(0.020)\end{array}$ & $\begin{array}{c}0.011 \\
(0.026)\end{array}$ & $\begin{array}{c}0.034 \\
(0.021)\end{array}$ \\
\hline Age & $\begin{array}{l}-0.003 \\
(0.004)\end{array}$ & $\begin{array}{c}0.005 \\
(0.006)\end{array}$ & $\begin{array}{l}-0.001 \\
(0.004)\end{array}$ & $\begin{array}{c}0.001 \\
(0.006)\end{array}$ & $\begin{array}{c}0.009^{* *} \\
(0.004)\end{array}$ \\
\hline Rural & $\begin{array}{l}-0.034 \\
(0.030)\end{array}$ & $\begin{array}{c}0.074^{* *} \\
(0.037)\end{array}$ & $\begin{array}{c}0.035 \\
(0.026)\end{array}$ & $\begin{array}{l}-0.040 \\
(0.035)\end{array}$ & $\begin{array}{c}-0.055^{* *} \\
(0.028)\end{array}$ \\
\hline Some Schooling & $\begin{array}{l}0.154^{*} \\
(0.079)\end{array}$ & $\begin{array}{c}0.005 \\
(0.114)\end{array}$ & $\begin{array}{l}-0.084 \\
(0.063)\end{array}$ & $\begin{array}{c}-0.207^{*} \\
(0.106)\end{array}$ & $\begin{array}{c}-0.026 \\
(0.064)\end{array}$ \\
\hline Secondary or Higher & $\begin{array}{c}0.201^{* *} \\
(0.080)\end{array}$ & $\begin{array}{c}0.048 \\
(0.115)\end{array}$ & $\begin{array}{c}-0.125^{* *} \\
(0.063)\end{array}$ & $\begin{array}{c}-0.266^{* *} \\
(0.107)\end{array}$ & $\begin{array}{c}0.025 \\
(0.065)\end{array}$ \\
\hline Observations & 1,991 & 1,991 & 1,991 & 1,991 & 1,991 \\
\hline$R^{2}$ & 0.37 & 0.10 & 0.03 & 0.18 & 0.37 \\
\hline Mean Dep. & 0.33 & 0.66 & 0.84 & 0.44 & 0.49 \\
\hline
\end{tabular}

Notes: All regressions include a country fixed effect. Additional controls include age, age-squared, male, urbanrural status, and a set of dummies for educational attainment. Individuals with missing control variables have their value set equal to the mean for their country with a dummy variable to mark the imputation.Robust standard errors to correct for heteroskedasticity in parenthesis. ${ }^{*} p<0.10,{ }^{* *} p<0.05,{ }^{* * *} p<0.01$ 
Table B4: Regression Knowledge and \# Protective Measures: Results by Country

\begin{tabular}{lcccc}
\hline & $(1)$ & $(2)$ & $(3)$ & $(4)$ \\
& Ghana & Malawi & Sierra Leone & Tanzania \\
\hline \# Correct Symptoms Listed & $0.092^{* *}$ & $0.327^{* * *}$ & $0.095^{* * *}$ & $0.150^{* * *}$ \\
& $(0.044)$ & $(0.047)$ & $(0.033)$ & $(0.036)$ \\
\# Correct Transmission Mechanisms & $0.230^{* * *}$ & $0.195^{* * *}$ & $0.282^{* * *}$ & $0.349^{* * *}$ \\
& $(0.081)$ & $(0.069)$ & $(0.056)$ & $(0.049)$ \\
Age & $-0.099^{*}$ & 0.004 & 0.029 & -0.015 \\
& $(0.056)$ & $(0.018)$ & $(0.023)$ & $(0.020)$ \\
Male & -0.181 & & 0.101 & 0.113 \\
& $(0.124)$ & & $(0.080)$ & $(0.074)$ \\
Rural & -0.129 & & & -0.074 \\
& $(0.137)$ & & & $(0.087)$ \\
Some Schooling & & -0.642 & $-0.523^{*}$ & 0.157 \\
& & $(0.392)$ & $(0.274)$ & $(0.210)$ \\
Secondary or Higher & & $-0.686^{*}$ & -0.394 & 0.307 \\
& & $(0.389)$ & $(0.268)$ & $(0.226)$ \\
\hline Observations & 277 & 491 & 633 & 557 \\
$R^{2}$ & 0.43 & 0.37 & 0.39 & 0.21 \\
Mean Dep. & 3.29 & 2.10 & 3.29 & 2.33 \\
\hline
\end{tabular}

Notes: All regressions include controls for age, age-squared, male, urban-rural status, a set of dummies for educational attainment, and enumerator fixed effects. Individuals with missing control variables have their value set equal to the mean for their country with a dummy variable to mark the imputation. The sample in Malawi is exclusively males in urban areas, and the sample in Sierra Leone is exclusively urban. Robust standard errors to correct for heteroskedasticity in parenthesis. ${ }^{*} p<0.10$, ** $p<0.05$, ,*** $p<0.01$ 


\section{Table B5: Regression Knowledge and Type of Contacts: Results by Location}

\begin{tabular}{lccccc}
\hline & $(1)$ & $(2)$ & $(3)$ & $(4)$ & $(5)$ \\
& Market & Work & Other Homes & Public Transport & Ate Restaurant \\
\hline \# Correct Symptoms Listed & 0.003 & -0.003 & 0.014 & 0.008 & -0.005 \\
& $(0.010)$ & $(0.009)$ & $(0.010)$ & $(0.010)$ & $(0.008)$ \\
\# Correct Transmission Mechanisms & 0.015 & 0.007 & $0.055^{* * *}$ & $0.046^{* * *}$ & $0.030^{* * *}$ \\
& $(0.015)$ & $(0.013)$ & $(0.015)$ & $(0.014)$ & $(0.011)$ \\
Male & $-0.082^{* * *}$ & $0.090^{* * *}$ & $0.048^{*}$ & 0.025 & $0.080^{* * *}$ \\
& $(0.028)$ & $(0.022)$ & $(0.028)$ & $(0.025)$ & $(0.016)$ \\
Age & $-0.013^{* *}$ & $0.015^{* * *}$ & $-0.010^{*}$ & 0.003 & $0.016^{* * *}$ \\
& $(0.006)$ & $(0.006)$ & $(0.006)$ & $(0.006)$ & $(0.005)$ \\
Rural & $-0.107^{* * *}$ & $0.070^{* *}$ & 0.027 & $-0.281^{* * *}$ & 0.007 \\
Some Schooling & $(0.037)$ & $(0.033)$ & $(0.037)$ & $(0.033)$ & $(0.027)$ \\
& 0.011 & 0.113 & -0.146 & 0.068 & 0.003 \\
Secondary or Higher & $(0.103)$ & $(0.095)$ & $(0.108)$ & $(0.085)$ & $(0.053)$ \\
& -0.024 & 0.102 & -0.130 & 0.091 & 0.029 \\
\hline Observations & $(0.103)$ & $(0.096)$ & $(0.109)$ & $(0.085)$ & $(0.053)$ \\
$R^{2}$ & 1,991 & 1,991 & 1,991 & 1,991 & 1,991 \\
Mean Dep. & 0.07 & 0.26 & 0.05 & 0.10 & 0.32 \\
\hline
\end{tabular}

Notes: All regressions include controls for age, age-squared, male, urban-rural status, a set of dummies for educational attainment, and enumerator fixed effects. Individuals with missing control variables have their value set equal to the mean for their country with a dummy variable to mark the imputation. Data on enumerator and schooling were not available for 72 respondents in Malawi. Robust standard errors to correct for heteroskedasticity in parenthesis. ${ }^{*} p<0.10,{ }^{* *} p<0.05,{ }^{* * *} p<0.01$ 
Table B6: Regression Knowledge and Number of Contacts: Results by Country

\begin{tabular}{|c|c|c|c|c|}
\hline & $\begin{array}{c}(1) \\
\text { Ghana }\end{array}$ & $\begin{array}{c}(2) \\
\text { Malawi }\end{array}$ & $\begin{array}{c}(3) \\
\text { Sierra Leone }\end{array}$ & $\begin{array}{c}(4) \\
\text { Tanzania }\end{array}$ \\
\hline \# Correct Symptoms Listed & $\begin{array}{c}0.105 \\
(0.090)\end{array}$ & $\begin{array}{c}-0.098 \\
(0.092)\end{array}$ & $\begin{array}{c}0.048 \\
(0.032)\end{array}$ & $\begin{array}{l}-0.021 \\
(0.079)\end{array}$ \\
\hline \# Correct Transmission Mechanisms & $\begin{array}{c}-0.026 \\
(0.114)\end{array}$ & $\begin{array}{c}0.265^{* *} \\
(0.125)\end{array}$ & $\begin{array}{c}0.200^{* * *} \\
(0.054)\end{array}$ & $\begin{array}{c}0.257^{* *} \\
(0.115)\end{array}$ \\
\hline \#Protective Measures (excluding social distancing) & $\begin{array}{c}0.038 \\
(0.092)\end{array}$ & $\begin{array}{c}0.241^{* *} \\
(0.105)\end{array}$ & $\begin{array}{c}0.148^{* * *} \\
(0.037)\end{array}$ & $\begin{array}{c}0.314^{* * *} \\
(0.100)\end{array}$ \\
\hline Age & $\begin{array}{c}0.005 \\
(0.089)\end{array}$ & $\begin{array}{c}0.017 \\
(0.039)\end{array}$ & $\begin{array}{l}-0.027 \\
(0.024)\end{array}$ & $\begin{array}{c}0.023 \\
(0.053)\end{array}$ \\
\hline Male & $\begin{array}{c}0.087 \\
(0.220)\end{array}$ & & $\begin{array}{c}0.118 \\
(0.074)\end{array}$ & $\begin{array}{c}0.411^{* *} \\
(0.173)\end{array}$ \\
\hline Rural & $\begin{array}{c}-0.457^{* *} \\
(0.224)\end{array}$ & & & $\begin{array}{c}0.054 \\
(0.180)\end{array}$ \\
\hline Some Schooling & & $\begin{array}{c}0.328 \\
(1.169)\end{array}$ & $\begin{array}{l}-0.137 \\
(0.523)\end{array}$ & $\begin{array}{c}0.757 \\
(0.613)\end{array}$ \\
\hline Secondary or Higher & & $\begin{array}{c}0.638 \\
(1.159)\end{array}$ & $\begin{array}{l}-0.291 \\
(0.522)\end{array}$ & $\begin{array}{c}0.377 \\
(0.638)\end{array}$ \\
\hline Observations & 277 & 562 & 597 & 555 \\
\hline$R^{2}$ & 0.04 & 0.04 & 0.10 & 0.14 \\
\hline Mean Dep. & 1.61 & 5.47 & 1.72 & 3.18 \\
\hline
\end{tabular}

Notes: All regressions include controls for age, age-squared, male, urban-rural status, a set of dummies for educational attainment, and enumerator fixed effects. Individuals with missing control variables have their value set equal to the mean for their country with a dummy variable to mark the imputation. Enumerator data were not available for 72 respondents in Malawi. Robust standard errors to correct for heteroskedasticity in parenthesis. ${ }^{*} p<0.10,{ }^{* *} p<0.05$, *** $p<0.01$ 